\title{
EEN NIEUW WERK OVER DE GESCHIEDENIS DER BENGAALSCHE TAAL EN LETTERKUNDE.
}

Door H. KERN.

Het is verblijdend te zien, dat hoe langer zoo meer geleerde Indiërs een werkzaam aandeel nemen in allerlei onderzoekingen die betrekking hebben op de geschiedenis van 't geestelijk leven in Indië van de vroegste tijden tot heden toe. Hun bijdragen tot vermeerdering onzer kennis zijn vooral te waardeeren wanneer het onderwerpen geldt die alleen door Indiërs van geboorte, levende in de Indische maatschappij, met gewenschte volledigheid kunnen behandeld worden. Zulk een onderwerp vormt den inhoud van 't onlangs verschenen werk "History of Bengali Language and Literature door Dinesh Chandra Sen, B. A., bevattende "A series of lectures delivered as Reader in the Calcutta University."

Dit statig boekdeel van 1010 bladzijden is de vrucht van jaren lang voortgezet onderzoek. Voor de samenstelling er van heeft de Schrijver met de grootste moeite een bijzonder rijk materiaal weten te verzamelen: honderden van handschriften, tot nog toe onbekend bij 't beschaafde Bengaalsche publiek, heeft hij opgespoord, ook bij de landbevolking, geklassificeerd en kritisch beschouwd. Verscheiden scholen van dichtkunst opgekomen in verschillende tijdperken van 't nationaal bestaan, zijn in verband gebracht met de natuurlijke historische oorzaken en van ongeveer hońderd schrijvers wordt een levensschets gegeven. De letterkunde van Oostelijk Bengalen was geheel onbekend; niemand dacht er aan, zelfs in geleerde kringen, dat er in Dacca, Tipperah en Chittagong Bengaalsche dichters geweest waren die 't gansche Rāmāyaṇa, Mahābhārata en een groot aantal andere werken aangaande Hindusche godsdienst en overleveringen in 't Bengaalsch vertaald hebben.

De groote verdienste van den Schrijver ligt niet uitsluitend 
daarin dat hij een zoo veelomvattende geschiedenis der Bengaalsche taal en letterkunde in 't licht heeft gegeven, maar ook daarin dat hij ons bekend maakt met de ontwikkeling van 't godsdienstig leven der bevolking gedurende de laatste duizend jaren, van welke ontwikkeling de letterkundige voortbrengselen een getrouwe uitdrukking zijn.

Er was een tijd dat de Bengaalsche bevolking voor ' $t$ meerendeel Buddhistisch of Jainistisch was. Veel beroemde Buddhistische leeraars waren uit Bengalen afkomstig, o. a. Atiç̧a (geb. 980' A. D.), de hervormer van 't Lamaisme in Tibet; Çāntirakṣita, een tijd lang Rector aan de Hoogeschool te Nālandā, Çílabhadra, e. a. Volgens de Jaina's hebben 23 van hun Tîrthańkara's hun verlossing in Bengalen bereikt. Die Tïrthankara's zijn wel louter legendarisch, maar de legende is toch kenschetsend voor de beteekenis van Bengalen als een land waar 't Jainisme bloeide.

Het dialekt waarin de Buddhisten hun geschriften opstelden was de volkstaal, het zgn. Gauḍa-prākṛt, d. i. het Prākrt van Gauḍa (West-Bengalen). De grammaticus Kṛṣna Paṇdita, die in de $12^{\text {de }}$ eeuw bloeide, vereenzelvigt dat dialect met het $\mathrm{zgn}$. Paiçāci-Prākṛt, doch ik houd dat voor een dwaling.

Verscheiden werken geschreven in de $10^{\text {de }}$ en $11^{\text {de }}$ eeuw, in een zeer ouden vorm van Bengaalsch, zijn in den laatsten tijd ontdekt door Haraprasāda Çāstrì in Nepāl. Het schijnen brokstukken te zijn van geschriften van Tantrisch-Buddhistischen inhoud.

Toen bij het toenemend verval van 't Buddhisme het Brahmanistisch Hinduïsme zich machtig deed gelden, werd de volkstaal geminacht en alleen 't Sanskrit waardig gekeurd als litteratuur- en hoftaal gebezigd te worden. Merkwaardig is het dat eerst de Mohammedaansche heerschers het Bengaalsch begunstigden. De Pāthānsche vorst van West-Bengalen Nasira Sjāh die van $128 \overline{\text { tot }} 1325$ heerschte, liet het Mahābhārata vertalen. Een andere vertaling van hetzelfde heldendicht door Kawindea Parameçwara kwam tót stand op bevel van Parāgal Chān, gouverneur van Chittagong. Het Bhāgavata-Purāṇa werd vertaald door Mālādhara Vasu in opdracht van Husein Sjāh. Het Rāmāyaṇa had tot vertaler Kṛttivāsa. Tal van andere geschriften in 't Bengaalsch dagteekenen uit den vroeger Mohammedaanschen tijd. Toen nu 't Bengaalsch, om zoo te zeggen in de mode gekomen was, werd het voorbeẻld der Moslimsche heerschers gevolgd door de Hindoesche Rāja's. 
De stukken in een geheel verouderd taaleigen, naar gissing uit de $10^{\text {de }}$ eeuw, vertoonen over 't geheel een boersch karakter. Zoo bevat de Dakārnava, waarvan een exemplaar in Nepāl teruggevonden is, alsook het Khanā-Vacana weervoorspellingen, astrologie, regelen voor huisbouw, geneesmiddelen, wijze gezegden, enz. Het zijn, kan men zeggen, encyclopaediën voor den landman. In jongeren vorm zijn beide geschriften nog zeer in- aanzien bij de landelijke bevolking. Andere werken uit hetzelfde tijdperk zijn Çūnyapurāṇa, Caryāarcaryaviniçcaya en Dharmamangala, alle drie Buddhistisch, al is het dan ook niet van de zuiverste soort.

Tot de volkslitteratuur behooren ook de balladen en liederen uit de $12^{\text {de }}$ eeuw, ongeslepen in vorm, maar gedeeltelijk treffend van inhoud.

Van de Hindusche secten wier geloof in de verschillende Purāna's een uitdrukking vindt, is in de eerste plaats te noemen ' $t$ Çivaïsme, hoewel het geenszins de meest verbreide was en overvleugeld werd, en nog is, door de meer populaire Çāktasekte, zoo geheeten omdat de Çakti of vrouwelijke energie van Çiva, onder den naam van Caṇdì, als hoogste voorwerp van aanbidding vereerd wordt. Nog in een andere sekte wordt het vrouwelijk beginsel als Manasā-Devì, de zgn. slangengodin, aangebeden. "The goddess Manasā Devì, zegt de Schrijver ${ }^{1}$ "who represents the divine power as seen in snakes has been a popular deity from very early times, but before her worship was recognised as a form of Chakti-worship, the followers of the Çaiva-religion offered a great resistance to it, as indeed they did to the worship of all other local deities of the later Çākta-cult».

Er bestaan veel Bengaalsche dichtwerken van aanhangers der genoemde sekten, geschreven tusschen de $13^{\text {de }}$ en de $18^{\text {de }}$ eeuw. Ze zijn met de noodige uitvoerigheid behandeld van p. 235 tot p. 363.

Een zeer voorname plaats in 't godsdienstig leven van Bengalen wordt ingenomen door 't Viṣnuïsme, in zijn latere ontwikkeling. Omtrent de beteekenis der Vaiṣnava-litteratuur laat zich de Schrijver aldus ${ }^{2}$ uit:

2 P. 399. 
"Works written by the Vaiṣnavas form the most important and interesting portion of our literature. They cover a varied field and contain the finest examples of poetry that are to be found in our language and are no less important for their lofty spiritual tone inspired by the great personality of Chaitanya Deva than for the influence they have exerted on our language in all its different channels".

De groote man wiens geest den stempel heeft gedrukt op de geheele Bengaalsche Vaișnava-litteratuur, was de vermaarde hervormer Chaitanya, wiens leven en leer met verklaarbare voorliefde door den Schrijver beschreven worden.

Chaitanya werd geboren in Navadvīpa in 1486. Zijn voorouders hadden gewoond te Jaipur in Orissa, doch zijn vader, Jagannātha Miçra, vestigde zich in Navadvīpa, waar hij trouwde en vader werd van tien kinderen, waarvan twee zoons. De jongste Viçvambhara, ook Nimāi genaamd, die later als Chaitanya beroemd zou worden, was een wilde knaap die allerlei streken uithaalde, zoodat zijn vader zich genoopt zag hem op de school te doen bij den Pạ̣ḍit Gangādāsa. De knaap toonde zich vlug van begrip en leerzaam, maar nog alles behalve zachtzinnig. Op twintigjarigen leeftijd opende hij zelf een school die van heinde en ver leerlingen lokte. Omtrent denzelfden tijd kwam een befaamd geleerde, Keçava van Kasjmir, te Navadvìpa, om , naar Indische gewoonte, andere geleerden uit te dagen tot een wedstrijd. Navadvīpa was toen de voornaamste zetel van geleerdheid in Bengalen. Keçava had geheel Indië doorgereisd en lauweren behaald, en kwam nu, om nieuwe te plukken in Navadvipa. De inwoners, die trotsch waren op Nimāi, brachten den ouden geleerde bij dezen, die hem hartelijk ontving. Keçava die ook dichter was, werd nu door hem uitgenoodigd den Gangres in een extempore gedicht te beschrijven, waarop de oude dichter een schitterende proeve van zijn talent gaf. Trotsch op zijn welgeslaagde dichterproeve, zeide hij tot Nimāi: "Gij hebt alleen Grammatica bestudeerd, naar ik hoor, en zijt niet ervaren in Rhetorica. Gij zijt niet in staat over de waarde van mijn gedicht te oordeelen". Doch Nimāi was dadelijk gereed om zooveel fouten in 't gedicht aan te wijzen, dat Keçava verbluft met een gebroken hart zich verwijderde.

Het was een hebbelijkheid van Nimāi, dat hij met godsdienst spotte, maar bij al zijn pronken met zijn scepticisme, schuilde 
in hem een godsdienstige zin. Zijn vertrouwelijke omgang met een paar eerbiedwaardige Brahmanen, die hij herhaaldelijk uitlachte, maar toch hoogelijk eerde, liet niet na op zijn ontvankelijk gemoed een diepen indruk achter te laten.

Onderwijl trad hij in 't huwelijk en verloor nagenoeg tezelfder tijd zijn vader. Uit droefheid over dat verlies, maakte hij, om zich te verzetten, een reis door oostelijk Bengalen, waar hij overal met onderscheiding ontvangen werd.

Bij zijne tehuiskomst vernam hij dat zijne gade tengevolge van een slangenbeet gestorven was. Het was alleen op aandrang zijner moeder dat hij hertrouwde, zonder dat zijne gewone opgeruimdheid terugkeerde. Er was een gevoel dat hem drukte. Hij verzocht zijne bejaarde moeder verlof om naar Gayā in Magadha te gaan ten einde Viṣnu te vereeren en aan de schim zijns vaders de gewone offerande te brengen.

Op zijn tocht naar Gayā bleek reeds hoe een groote verandering over zijn geheele wezen gekomen was. Te Gayā bracht hij zijne bloemenofferande aan Viṣnu, den grooten God, terwijl de priesters hun lofzang lieten weerklinken. Als wezenloos, lette hij niet op de woorden van 't lied, slechts vloeiden hem de tranen over de wangen, en hij viel in zwijm. Toen hij weêr bijgekomen was, zeide hij tot zijne makkers: «Verlaat mij, vrienden, verlaat mij; ik ben niet meer geschikt voor deze wereld. Laat mij gaan naar 't Vụndāvana om Kṛṣna te vinden, mijn Heer en den Heer van 't Heelals. In half bewusten toestand werd hij door zijne gezellen weder naar zijn woonplaats gevoerd. Zijne moeder, ontsteld over zijn toestand, liet geneesheeren ontbieden, doch hij verklaarde geen ziekte te hebben die door geneesmiddelen kon geheeld worden. De Allerhoogste was hem verschenen en hij kon aan niets anders denken.

Van toen af, kan men zeggen, begon zijn loopbaan als verkondiger van een gelouterd Viṣnuisme en bij zijne woorden voegde hij de daad: het was zijn lust de lasten van ouden en zieken te verlichten, zelfs dienstwerk te verrichten wat aan Brahmanen verboden is. In 't algemeen loochende hij de geldigheid van 't kastenstelsel, en verklaarde hij stoutweg: $\mathrm{Al}$ is iemand een Paria, indien hij vroom is en God liefheeft, is hij verheven boven de Brahmanen».

Het optreden van den moedigen hervormer stuitte, zooals licht te begrijpen is, op heftigen tegenstand, hetgeen niet verDl. 67 . 
hinderde dat onder alle klassen der bevolking zijn aanhang onophoudelijk toenam. Begrijpende dat hij als leek aan verwijten blootstond, besloot hij een Sannyāsin, een wereldverzaker, te worden. Tot dien stap ging hij over in 1509, van welken tijd hij den naam Kṛṣna Chaitanya aannam.

Om zijn werk voort te zetten begaf hij zich naar Orissa, en voorts reisde hij over geheel Zuid-Indië. Na overal bekeerlingen gemaakt te hebben, keerde hij terug naar Puri, en ging van daar naar Vṛndāvana, waar hij zes jaar bleef. Toen vestigde hij zich weder te Puri, en bleef daar tot aan zijn dood in 1534.

Van de talrijke geschriften die op Chaitanya en zijne werkzaamheid betrekking hebben en van de omvangrijke Bengaalsche Vaiṣnava-litteratuur in 't algemeen, wordt een volledig overzicht gegeven p. 444-565.

Het VIde Hoofdstuk der History behandelt de gewrochten der Bengaalsche Muze uit het tijdperk dat ligt tusschen den dood van Chaitanya en 't einde der $18^{\text {de }}$ eeuw.

Merkwaardig is het dat een der beste schrijvers een Mohammedaan was, Alāol (geb. \pm 1618 ), die vertalingen leverde van Hindì en Perzische gedichten en verzen maakte op Kṛṣna en Rādhā. Hij was de eerste die een overmatig gebruik makte van Sanskritwoorden, zoodat men zijne taal een gesanskritiseerd Bengaalsch kan noemen. Zijn voorbeeld heeft maar al te veel navolging gevonden.

Een reeks van dichters hebben achtereenvolgens de minnarijen bezongen van Vidyā en Sundara, wel een bewijs dat het onderwerp bijzonder in den smaak viel. De meest gezochte van die verschillende bewerkingen der stof is die door Bhārata Chandra Rāi (geb. 1722, in Basantapur, gest. 1760). Als waardige mededingers van Bhārata Chandra worden beschouwd Jaya-nārāyaṇa en diens nicht, de dichteres Ānandamayî̀. Er is veel in die geschriften wat de zinnelijkheid prikkelt, en de dichters die den stijl van Bhārata Chandra navolgden, lieten in de laatste helft der $18^{\text {de }}$ eeuw werken verschijnen, zóó onzedelijk dat de verspreiding er van door 't Indische Strafwetboek onderdrukt is.

In tegenstelling tot de aanstootelijke gedichten die een bedorven stads- en hoflucht ademen, staan de voortbrengselen der landelijke Muze. "The vices of the towns», zegt onze Schrijver, "stamped the litarature of the courts degrading it 
to wicked sensualism; the vain pedantry of scholars introduced into it erudite absurdities of far-fetched imagery. - But the quiet Hindre was not in his element in the city. De landelijke litteratuur bestaat uit liederen, waarvan een bepaalde soort, gewoonlijk betrekking hebbende op de liefde van Kṛșna en Rādhā, of op huiselijke tooneelen in 't verblijf van Çiva op den Kailāsa gezongen plegen te worden door rondreizende meistreelen, Kavivalla's, vereenigd in partijen van mannen en vrouwen, die in koor zingen. Die liederen waren oorspronkelijk gedeelten van Yātrā's of primitieve tooneelvoorstellingen. Door de opkomst van 't nieuwe Bengaalsche tooneel zijn de Yātrā's met de liederen weinig meer in zwang. Ettelijke liederdichters bloeiden nog in de eerste helft der $19^{\text {de }}$ eeuw; toch is van Engelschen invloed bij hen niets te bespeuren.

Onder de dichters van godsdienstige liederen munt uit Rāmaprasāda Sen, een Vaidya, die in zijne zangen de godin Kālí als barmhartige Moeder verheerlijkt.

Nog te vermelden zijn de liederen van de oude Yātrā's, een soort van melodrama's, waarin de dialogen hoofdzakelijk in zang zijn.

Het nieuwe tijdperk der Bengaalsche letteren word ingewijd door Europeanen, zendelingen en ambtenaren. De eerste spraakkunst van 't Bengaalsch is te danken aan Halhed (1778); de invoering der eerste druktypen aan Wilkins; een netter en kleinere type werd ingevoerd door Dr. Carey. Deze laatste (gest. 1834), heeft zich als schrijver van Bengaalsche werken en anderszins jegens de ontwikkeling der litteratuur hoogst verdienstelijk gemaakt, zooals de Schrijver dankbaar erkent. Carey was zeer ingenomen met het Bengaalsch. "This language» zegt hij, "when properly cultivated, will be inferior to none in elegance and perspicuity.» Onder zijne Bengaalsçhe geschriften verdient vermelding "Itihāsamālā, of krans van vertellingen», uitgekomen in 1812. Het bevat 150 korte verhalen te dier tijde onder 't volk in omloop. Zijn eenvoudige prozastijl vond veel navolgers onder de landzaten.

Carey was niet de eenige Europeaan die in 't Bengaalsch schreef. Talrijke werken van allerlei aard, wetenschappelijke handboeken, vertalingen, wetboeken, geschiedenis, enz. zijn van Europeanen. In 't algemeen kan men zeggen dat Europeanen, voornamelijk zendelingen "de pioniers waren in alle takken van 
geschriften in de landstaal welke bij de ontwaking van den Indischen geest onder 't Engelsch bestuur in gunst kwamen. „ 1

Een gunstigen invloed op de beoefening van taal- en letterkunde is uitgeoefend door 't College of Fort William. De Pandits aan die instelling hebben uitmuntende bijdragen geleverd, ook tot de wetenschappelijke litteratuur. Niet minder verdienstelijk waren de geleerde werken van Kṛṣna Mohan Banerji, die in 1832 het Christendom omhelsde. Een reeks van andere wetenschappelijke geschriften wordt in de "History» vermeld p. 900, waarop volgt een opsomming van verhalen en verhandelingen, periodieken, enz. Zeer lezenswaard zijn de opmerkingen over 't karakter van den nieuwen tijd in tegenstelling tot het verleden.

De zedelijke toestanden in 't Bengalen der $18^{\text {de }}$ eeuw waren allertreurigst; het godsdienstig leven was tot een laag peil gedaald; het jonge geslacht dat onder den invloed kwam van Westersche denkbeelden voelde dat een zuivering der misbruiken nood deed, doch in plaats van te hervormen poogde zij de geheele Indische maatschappij te ontwrichten. Toen trad als hervormer een groot man op, wiens naam door allen die met hem in aanraking kwamen of alleen zijne werken kennen met eerbied genoemd wordt, de edele Rāma Mohana Roy: Deze brahmaan, wiens buitengewone begaafdheden gepaard gingen met hoogheid van karakter en een onberispelijken levenswandel, werd geboren 1774 te Rādhānagar in 't Hughli-district. Hij was een door en door godsdienstig man, maar tevens verwierp hij alle Hindusche praktijken en verklaarde ze voor afgoderij. Zijn geheele leven heeft hij geijverd om zijne verlichte denkbeelden onder zijn landgenooten te verbreiden. Reeds op 16-jarigen ouderdom kwam hij in verzet tegen de afgoderij; vier jaar later kwam hij voor 't eerst in aanraking met Europeanen, wier goede hoedanigheden hij erkende. Het hoofddenkbeeld waarvan hij bij zijn bestrijding van bijgeloof uitging heeft hij in zijne Autobiography aldus uitgedrukt: "The ground which I took in all controversies was, not that of opposition to Brahminism, but to a perversion of it; and I endeavoured to show that the idolatry of the Brahminism was contrary to the practice of their ancestors, and the principles in the ancient books and authorities which they profess to revere and obey». 
In 1831 kwam Rāma Mohana Roy in Engeland. Op uitnoodiging van een Commissie van 't Lagerhuis legde hij voor dat lichaam getuigenis af aangaande 't stelsel van rechtspleging en belastingen, alsook over den toestand der inlandsche bevolking. Voor een niet gering deel was het aan zijn toedoen te danken dat het uit Indië ingekomen rekwest om het verbod tegen de weduwverbranding weêr af te schaffen, verworpen werd. Hij heeft niet lang in Europa geleefd, hij stierf te Bristol 27 Sept. 1838.

De hervorming die de edele man en warme vriend van zijn volk predikte heeft niet zooveel ingang gevonden als ze verdiende, maar is toch niet geheel zonder vrucht gebleven. Ook zijne litterarische werkzaamheid is der ontwikkeling der nationale letterkunde ten goede gekomen. Omtrent de schrijvers die hem volgden vindt de lezer volledig bescheid, p. 936-p. 1002.

De Heer Dinesh Chandra Sen heeft zijn hoogst belangrijk boek, van welks rijken inhoud wij slechts een mager uittreksel hebben kunnen geven, verrijkt met eenige illustraties, waarvan bijzondere opmerking verdienen: een reproductie van een schilderij, vervaardigd tusschen 1512 en 1538, en voorstellende Chaitanya luisterende naar 't Bhāgavata; voorts de portretten van Dr. Carey en Rāma Mohana Roy. 